stomatologie 2013 [Suppl 1] · 110:24-24

DOI 10.1007/s00715-013-0256-7

๑) Springer-Verlag Wien 2013

\section{Festrede des Vereinspräsidenten Karl Jarisch zum 50-jährigen Jubiläum des VÖZ}

\author{
Ordentliche Hauptversammlung \\ am 14. November 1911
}

„Meine hochgeehrten Herren!

Ich eröffne die 50. Hauptversammlung unseres Vereines und konstatiere die Beschlussfähigkeit derselben. Es ist ein feierlicher Moment, in dem ich zu Ihnen spreche. Bis auf die Stunde ist es ein halbes Jahrhundert, dass unser Verein ins Leben gerufen wurde. Das älteste Mitglied, Dr. Eduard M ü h l r e d e r, der ja auch unser Ehrenmitglied ist, ist leider durch sein hohes Alter verhindert, eine so weite Reise zu unternehmen, um den Ehrenvorsitz in der heutigen Sitzung zu führen; aber er hat in rührender Weise seine treue Anhänglichkeit an den Verein und seine innigsten Wünsche für das weitere Gedeihen desselben schriftlich zum Ausdruck gebracht und ich bitte um ihre Einwilligung, ihm auf telegraphischem Wege unsere achtungsvollsten Grüße senden zu dürfen. Und so obliegt es denn mir, als dem zweitältesten Mitglied, der alten Zeiten $\mathrm{zu}$ gedenken, und es ist eine Flut von Erinnerungen, die in diesem Augenblicke auf mich einstürmt. Ich sehe vor mir das alte Haus auf der Brandstätte, in dem $\mathrm{H}$ e i d e r wohnte, ich sehe noch die steile, hölzerne Treppe, die zu seiner Wohnung führte, das Wohnzimmer mit den alten, wahrscheinlich noch aus $\mathrm{C}$ a $\mathrm{r}$ a b e $\mathrm{l}$ 1 i s Zeiten stammenden Möbeln, in einer Fensternische den ungeschlachten Operationssessel mit der hohen Lehne und das sehr bescheidene Instrumentarium. Ich sehe die alten Herren, die in geringer Zahl die Sitzungen besuchten und in ihrer Mitte die schlanke elegante Gestalt des Grün- ders, $\mathrm{H}$ e i d e r s. Man braucht nur dieses alte Erinnerungsbild zu vergleichen mit dem Bilde, das ein modernes zahnärztliches Atelier heute bietet, so wird der Unterschied von einst und jetzt mächtig auf die Seele wirken. In diesen einfach ausgestatteten, nur mit dem nach unseren heutigen Begriffen notdürftigsten beruflichen Hausrate versehenen Räumen wurde das Samenkorn in den Boden gesenkt, aus dem sich zwar langsam, aber genährt durch die Bemühungen nachkommender jüngerer Kräfte ein starker Stamm entwickelte, der heute die schönsten Früchte trägt. Den Männern aber, die das Samenkorn gepflanzt, gebührt heute unsere dankbarste Erinnerung. Nicht Nekrologe wollen wir sprechen, nein, wir wollen vielmehr der Freude darüber Ausdruck geben, das wir sie besessen haben, das sie unser waren, und ihre Verdienste anzuerkennen, ist unsre heilige Pflicht, denn nur aus dem Alten kann Neues entspringen. Unser Verein ist eine Stätte des freundschaftlichen, ich möchte sagen, fast familiären Verkehres geworden, in dem jeder nach Maß seiner Kräfte lehrend wirkt oder von andern lernt. Hier finden wir Anregung und Aufmunterung und Rat. Jedem von uns Praktikern kann es passieren, dass ihm die Ätiologie, Diagnose oder die Therapie in einem gegebenen Falle nicht klar ist. Hier im Vereine steht ihm eine große Anzahl von Konsiliaren zu Gebote, die stets bereit sind, mit ihrer größeren Erfahrung, mit ihrem tieferen Wissen belehrend und ratend zur Seite stehen. Wenn unser Verein zu einer schönen Blüte gediehen ist, so hat er dies Ihnen, Ihrem einmütigen Zusammenwirken, Ihrer Strebsamkeit zu verdanken. An dieser Tatsache kann nicht gerüttelt werden und sie findet besonders bei dem Jubiläumsfeste, das heute seinen Anfang nimmt, ihre Erhärtung. Der Charakter und der geistige Standpunkt eines Vereines ist am besten an den Leistungen seiner Mitglieder zu erkennen, und die Festschrift wird die wertvollste Zierde unseres Festes auch für spät nach uns kommende Mitglieder bleiben. Den hochgeehrten Herren, die durch ihre hervorragenden Arbeiten diese Festschrift weit über das Niveau gewöhnlicher Gelegenheitsschriften gehoben haben, gebührt der wärmste Dank des Vereines ...“

Regierungsrat Dr. Karl Jarisch Präsident 